\title{
Detection of Jak2 V617f Mutation, Secondary to the Presence of Bcr-Abl1 Translocation in a Patient with Chronic Myeloid Leukemia: Report of a Case and Review of the Literature
}

\author{
Claudia Carranza*, Damaris Tinti, Mariana Herrera, Luisa Rosales, Mauricio Villegas and Gabriel Silva \\ Molecular Laboratory, Institute for the Research in Genetic and Metabolic Diseases, Invegem, Guatemala
}

\begin{abstract}
The myeloproliferative neoplasms are classified in four major diseases: Chronic Myeloid Leukemia, Polycythemia Vera, Primary Myelofibrosis and Essential Thrombocythemia. The JAK2 V617F mutation is found in 95\% of Polycythemia Vera, and $50 \%$ of Essential Thrombocythemia and Primary Myelofibrosis patients. It was thought that the JAK2 V617F mutation and BCR-ABL1 translocation were mutually exclusive; but now a few cases have been reported with both alterations. We report a rare case with the presence of JAK2 V617F mutation, secondary to a diagnosis of BCR-ABL positive chronic myeloid leukemia. The patient was initially diagnosed as chronic myeloid leukemia and was BCR-ABL1 positive, so he started to receive Imatinib. He responded well to the therapy for three years, but after this time the patient had a hematological relapse still with no detectable copies of BCR-ABL1. For this reason, we thought of the possible development of another genetic alteration. Because the patient had a very high platelet count, we decided to look for the JAK2 V617F mutation, which result was positive. This case is just one of the few that have been reported worldwide that have a coexistence of these two genetic alterations: the BCR-ABL1 transcript and JAK2 V617F mutation in chronic myeloproliferative syndromes. This is the first case in the Central American population, found in our series of a total of 168 patients with Philadelphia positive chronic myeloid leukemia.
\end{abstract}

Keywords: BCR-ABL1; JAK2; Coexistence; Myeloproliferative neoplasm

\section{Introduction}

The Myeloproliferative Neoplasms (MPN) are classified as four major diseases: Chronic Myeloid Leukemia (CML), Polycythemia Vera (PV), Primary Myelofibrosis (PMF) and Essential Thrombocythemia (ET) [1]. The translocation $\mathrm{t}(9 ; 22)(\mathrm{q} 34 ; \mathrm{q} 11)$ produces the Philadelphia chromosome and causes the $B C R-A B L 1$ transcript; this alteration is commonly found in CML [1]. In 2008 the World Health Organization (WHO) reported that MPN patients with the BCR-ABL1 transcript (Philadelphia positive) should be classified as chronic myeloid leukemia, and those who are Philadelphia negative (BCR-ABL1 negative) should be classified as Polycythemia Vera (PV), Essential Thrombocytosis (ET ) or myelofibrosis (PMF) [1]. JAK2 is a tyrosine kinase gene that has a role in the signaling pathways of hematopoietic factors. The JAK2 V617F mutation is found in $95 \%$ of PV patients, and 50\% of ET and PMF patients $[2,3]$. Previously, it was thought that the JAK2 V617F mutation and $B C R-A B L 1$ translocation were mutually exclusive. However a few rare cases have been reported that are positive for both alterations [4-17]. We report the first case in Central American with the presence of $J A K 2 \mathrm{~V} 617 \mathrm{~F}$ mutation, in a patient with the diagnosis of Philadelphia positive chronic myeloid leukemia.

\section{Material and Methods}

\section{Patients' samples}

We collected blood samples from patients with a diagnosis of myeloproliferative neoplasm. The samples were collected from patients referred from different national hospitals. Every patient signed the informed consent form approved by the local ethics committee. The technique used for extracting leukocytes from blood was via ammonium lysis. Cells obtained by this technique were stored at $-20^{\circ} \mathrm{C}$.

\section{Case report information}

All the information analyzed in this case report was given by the patient and the participant hospitals. The diagnosis of the BCR-ABL1 transcript was made by FISH by other national laboratory.

RNA AND DNA EXTRACTION: The RNA was extracted by the trizol (Life technologies, NY, USA) method according to the manufacture's procedures. The DNA was extracted using the Purelink Genomic DNA Minikit (Invitrogen, NY, USA). The RNA and DNA quantitation was made by fluorometry, using the quantifluor equipment and method (Promega, WI, USA).

\section{JAK2 V617F Allele specific-PCR}

The reaction was standardized according to the thermal cycler used. The primers used were described by Jones et al. and Chen, et al. $[18,19]$. The PCR conditions included 10 minutes at $94^{\circ} \mathrm{C}, 30$ cycles each of 30 seconds at $94^{\circ} \mathrm{C}, 45$ seconds at $54^{\circ} \mathrm{C}, 1$ minute at $72^{\circ} \mathrm{C}$, and a final extension of 5 minutes at $72^{\circ} \mathrm{C}$.

\section{BCR-ABL1 real time PCR quantitation}

The real time PCR was made according the Molecular MD OneStep qRT-PCR BCR-ABL kit procedures. (Molecular MD, Portland OR, USA).

*Corresponding author: Claudia Carranza, Molecular Laboratory, Institute fo the Research in Genetic and Metabolic Diseases, Invegem, Guatemala, Tel: (502) 40507444; E-mail: ccarranza@invegem.org

Received December 05, 2013; Accepted March 03, 2014; Published March 13 , 2014

Citation: Carranza C, Tinti D, Herrera M, Rosales L, Villegas M, et al. (2014) Detection of Jak2 V617f Mutation, Secondary to the Presence of Bcr-Abl1 Translocation in a Patient with Chronic Myeloid Leukemia: Report of a Case and Review of the Literature. Int J Genomic Med 2: 116. doi: 10.4172/23320672.1000116

Copyright: (c) 2014 Carranza C, et al. This is an open-access article distributed under the terms of the Creative Commons Attribution License, which permits unrestricted use, distribution, and reproduction in any medium, provided the original author and source are credited. 
Citation: Carranza C, Tinti D, Herrera M, Rosales L, Villegas M, et al. (2014) Detection of Jak2 V617f Mutation, Secondary to the Presence of BcrAbl1 Translocation in a Patient with Chronic Myeloid Leukemia: Report of a Case and Review of the Literature. Int J Genomic Med 2: 116. doi: 10.4172/2332-0672.1000116

Page 2 of 4

\section{Results}

\section{Case presentation}

In November, 2010 a Guatemalan man of 68 years presented with a problem of thrombosis in one finger. Initial laboratory tests showed that the white cell count was $22.7 \times 10^{3} / \mathrm{ml}$ with $86.8 \%$ neutrophils, $6.9 \%$ lymphocytes, $2.2 \%$ monocytes $3.7 \%$ eosinophils and $0.4 \%$ basophils. The red blood count was $7.12 \times 10^{6} \mathrm{ml}$, the hemoglobin was $18 \mathrm{mg} / \mathrm{ml}$, the HCT was $55.50 \%$ and the platelets count was $6.97 \times 10^{5} \mathrm{~mL}$. Bone marrow analysis was compatible with a chronic myeloproliferative process. FISH analysis revealed the chromosome translocation $t(9 ; 22)$ ( $\mathrm{q} 34 ; \mathrm{q} 11)$. From this, the patient was diagnosed as chronic myeloid leukemia $B C R-A B L 1$-positive. The patient was treated with $400 \mathrm{mg}$.
Imatinib, and then the dose was increased to $800 \mathrm{mg}$ since there was not a complete hematologic response. The patient reached hematologic remission, and remained there, until January 2013, at which time the patient had a hematological relapse.

Molecular monitoring of $B C R-A B L 1$ copy numbers, began in November 2011 (one year after diagnosis) and was at $0.06 \%$ IS (international system), which means a major molecular response (MMR) to therapy; unfortunately there were no monitoring of $B C R$ $A B L 1$ prior to this date. Four additional $B C R-A B L 1$ monitoring were conducted periodically, and all showed a complete molecular response. The last monitoring was performed in April 2013 (Figure 1). Note that the patient has no detectable copies $B C R-A B L 1$, yet still has clinically

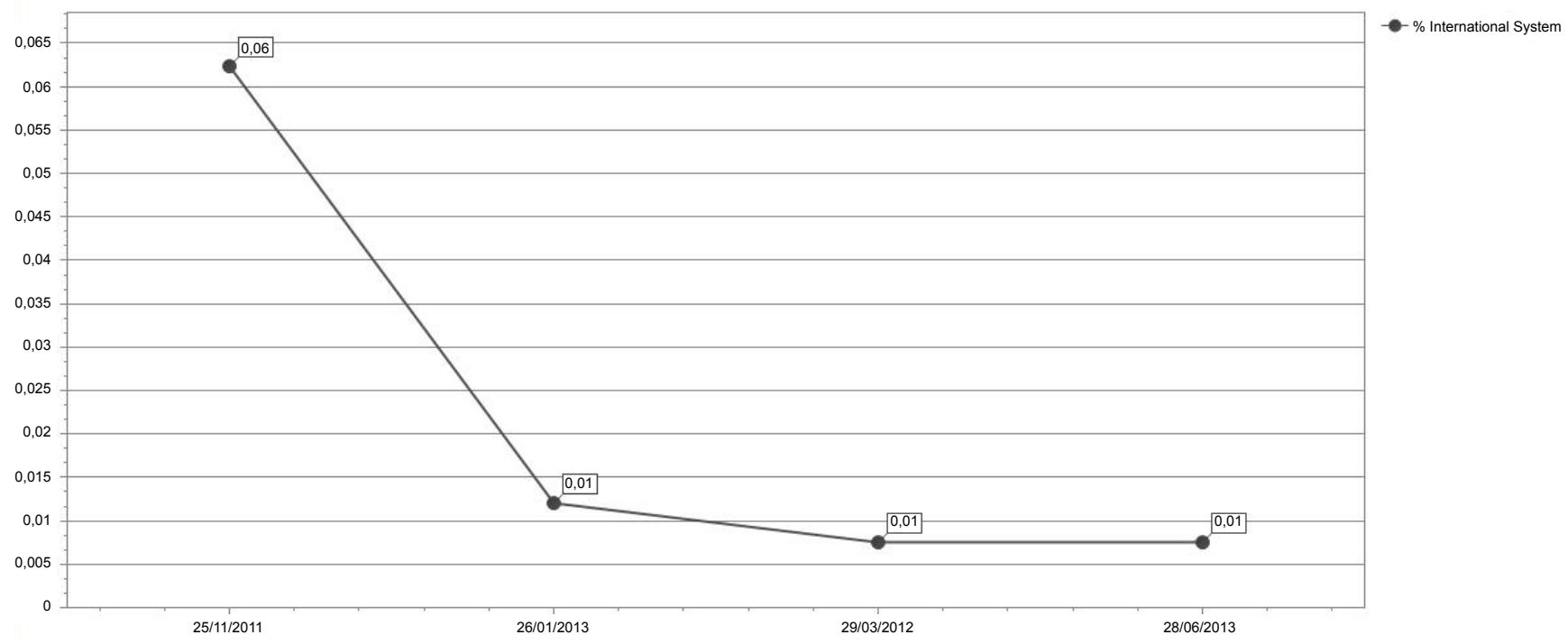

Figure 1: $B C R-A B L 1$ MOLECULAR MONITORING, showing the initial major molecular response and then the complete molecular response in each monitoring.

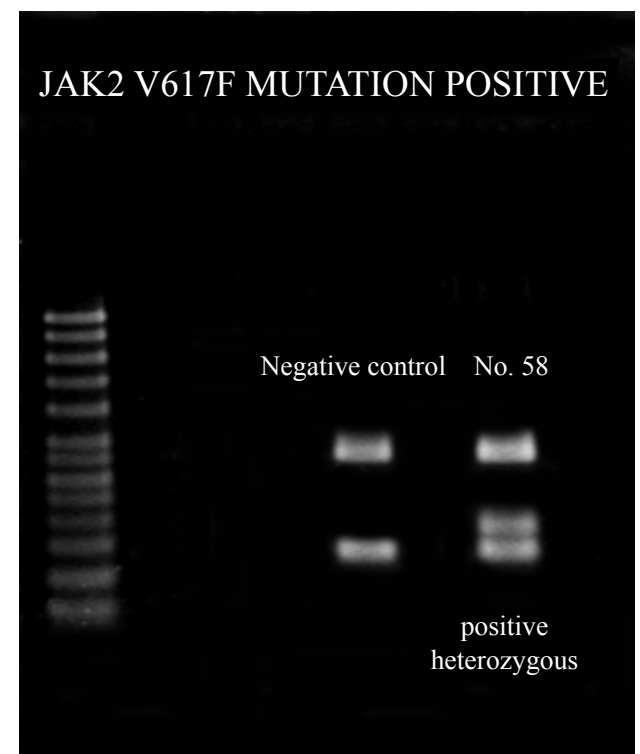

Figure 2: JAK2 V617F, This figure shows the presence of JAK2 V617F heterozygous mutation. 
Citation: Carranza C, Tinti D, Herrera M, Rosales L, Villegas M, et al. (2014) Detection of Jak2 V617f Mutation, Secondary to the Presence of BcrAbl1 Translocation in a Patient with Chronic Myeloid Leukemia: Report of a Case and Review of the Literature. Int J Genomic Med 2: 116. doi: 10.4172/2332-0672.1000116

Page 3 of 4

\begin{tabular}{|c|c|c|c|c|c|}
\hline $\begin{array}{l}\text { INITIAL } \\
\text { DIAGNOSIS }\end{array}$ & $\begin{array}{l}\text { NUMBER OF } \\
\text { CASES }\end{array}$ & $\begin{array}{l}\text { PRESENCE OF BCR-ABL1 AND JAK2 } \\
\text { MUTATION }\end{array}$ & AGE & $\begin{array}{l}\text { LEUKOCYTES COUNT } \\
\left(\times 10^{3} / \mathrm{ml}\right)\end{array}$ & PLATELETS $\left(\times 10^{5} / \mathrm{ml}\right)$ \\
\hline CML & 3 & $\begin{array}{l}\text { Coexistence of both genetic alterations at } \\
\text { diagnosis }\end{array}$ & $21-67$ years & $38.0-143.0$ & $3.45-4.40$ \\
\hline CML & 4 & $\begin{array}{c}\text { Presence of BCR-ABL1 at diagnosis, and } \\
\text { subsequent development of the JAK2 } \\
\text { mutation }\end{array}$ & $42-53$ years & $36.7-350.0$ & $3.45-9.83$ \\
\hline MPN & 7 & $\begin{array}{l}\text { Coexistence of both genetic alterations at } \\
\text { diagnosis }\end{array}$ & $27-66$ years & $7.2-25.9$ & $2.85-8.3$ \\
\hline MPN & 2 & $\begin{array}{c}\text { Presence of JAK2 at diagnosis, and } \\
\text { subsequent development of the BCR-ABL1 } \\
\text { translocation }\end{array}$ & ---------- & $19.7-20.0$ & 7.5 \\
\hline
\end{tabular}

Table 1: Summary of Cases Reported [4-19]

relapsed. In June 2013, the laboratory tests showed that the white cell count was $17.2 \times 10^{3} \mathrm{ml}$, while the differential blood count showed $82.8 \%$ neutrophils, $9.41 \%$ lymphocytes, $4.01 \%$ monocytes $3.49 \%$ eosinophils and $0.30 \%$ basophils. The red blood count was $6.23 \times 10^{6} \%$ $\mathrm{ml}$, the hemoglobin $13.2 \mathrm{mg} / \mathrm{ml}$, the HCT $43.43 \%$ and a platelets count was $7.39 \times 10^{5} / \mathrm{ml}$. Because of the absence of a hematologic response to therapy, and the complete molecular response of $B C R / A B L 1$ presented by the patient, it was thought that another genetic alteration might coexist.

Because of the results of the last hematology studies in which both the platelet and white blood cell counts were increased, it was believed that this patient had a myeloproliferative neoplasm which was $B C R$ $A B L 1$ positive in combination with a mutation in the JAK2 gene. Therefore, we performed a test of the JAK2 V617F mutation by allelespecific PCR, and a positive heterozygous result was obtained for this mutation. The JAK2 mutation appeared after three years of having the BCR-ABL1 translocation, when the patient relapsed (Figure 2).

\section{Discussion}

The JAK2 gene and the ABL1 gene regulate hematopoietic function. The JAK2 mutations leads to uncontrolled cell proliferation and produces clinical characteristic compatible with MPN. The BCR-ABL1 translocation produces an imbalance in cell division, differentiation and apoptosis, this produce a CML. The two alterations are present in this patient. The high platelet counts show the presence of a MPN syndrome, secondary to the CML presentation.

As mentioned in the introduction, the $B C R-A B L 1$ transcript and $J A K 2$ mutation were previously believed to be mutually exclusive (according to the WHO criteria, 2008); and the presence of either one was used to classify the MPNs into two main groups: Philadelphia positive chronic myelogenous leukemia and Philadelphia negative MPNs, which are PV, ET, PMF. However a few cases have been reported in which there was a co-existence of two genetic alterations. In some of these the $B C R-A B L 1$ and JAK2 mutations were found to co-exist [3-11].

This case is the first reported from Central American and one of the few reported internationally, where the patient was initially diagnosed as having Philadelphia positive chronic myeloid leukemia, and in the following years developed the presence of the JAK2 V617F mutation. This is the first such case among 168 Guatemalan patients with Philadelphia positive chronic myeloid leukemia that we have studied.

As can be observed, our patient had a complete hematologic response only with a dose of $800 \mathrm{mg}$ of Imatinib, although the recommended dose is half of that. After the patient remained well for three years, he relapsed. We discarded Imatinib resistance as an explanation of the relapse since the monitoring of $B C R-A B L 1$ quantification indicated a continuing complete molecular response. Therefore, it was thought that the relapse was due to the presence of a secondary genetic alteration, which had subsequently developed in the presence of the $B C R-A B L 1$ transcript. For this reason, we investigated the presence of the JAK2 V617F mutation and a heterozygous positive result was obtained. No other cytogenetic or molecular abnormalities were found.

We concluded that the alteration that caused the loss of complete hematologic response was the JAK2 V617F mutation, secondary to the presence of $B C R-A B L 1$ transcript in a patient with chronic myeloid leukemia.

In Table 1, is shown a summary of the similar reported cases. There is a wide clinical variety of the co-existence of BCR-ABL1 and JAK2 mutations. Some patients present the both alterations at diagnosis and some present one first and then the other. Only four cases reported the initial diagnosis of chronic myeloid leukemia BCR-ABL1 positive, have been initially treated with Imatinib, and after years of treatment have relapsed and subsequently shown the secondary JAK2 mutation. This is the fifth case with these features.

\section{Acknowledgment}

We appreciate the financial support of the National Secretariat of Science and Technology -SENACYT-, through its FODECYT division and the Rozas-Botran Foundation.

\section{References}

1. Tefferi A, Vardiman JW (2008) Classification and diagnosis of myeloproliferative neoplasms: the 2008 World Health Organization criteria and point-of-care diagnostic algorithms. Leukemia 22: 14-22.

2. Baxter EJ, Scott LM, Campbell PJ, East C, Fourouclas N, et al. (2005) Acquired mutation of the tyrosine kinase JAK2 in human myeloproliferative disorders. Lancet 365: 1054-1061.

3. Tefferi A (2007) JAK2 mutations in polycythemia vera--molecular mechanisms and clinical applications. N Engl J Med 356: 444-445.

4. Toogeh G, Ferdowsi S, Naadali F, Alimoghaddam K, Ghavamzadeh A, et al. (2011) Concomitant presence of JAK2 V617F mutation and BCR-ABL translocation in a pregnant woman with polycythemia vera. Med Oncol 28 $1555-1558$.

5. Krämer A, Reiter A, Kruth J, Erben P, Hochhaus A, et al. (2007) JAK2-V617F mutation in a patient with Philadelphia-chromosome-positive chronic myeloid leukaemia. Lancet Oncol 8: 658-660.

6. Conchon MR, Costa JL, Novaes MM, Dorlhiac-Llacer PE, de Alencar Fische Chamone D, et al. (2008) Simultaneous detection of JAK2 V617F mutation and Bcr-Abl translocation in a patient with chronic myelogenous leukemia. Int J Hematol 88: 243-245.

7. Cappetta M, Pérez V, Zubillaga MN, Elizondo V, Manrique G, et al. (2013) Concomitant detection of BCR-ABL translocation and JAK2 V617F mutation in five patients with myeloproliferative neoplasm at diagnosis. Int J Lab Hematol 35: e4-5.

8. Park SH, Chi HS, Cho YU, Jang S, Parak CJ, et al. (2013) Two Cases of Myeloproliferatie Neoplasm with a Concurrent JAK2V617F Mutation and BCR/ABL Translocation without Chronic Myelogenous Leukemia Phenotype Acquisition during Hydroxyurea Treatment. Ann Lab Med 33: 229-232. 
Citation: Carranza C, Tinti D, Herrera M, Rosales L, Villegas M, et al. (2014) Detection of Jak2 V617f Mutation, Secondary to the Presence of BcrAbl1 Translocation in a Patient with Chronic Myeloid Leukemia: Report of a Case and Review of the Literature. Int J Genomic Med 2: 116. doi: 10.4172/2332-0672.1000116

9. Gattenlohner S, Völker HU, Etschmann B, Einsele H, Müller-Hermelink HK (2009) BCR-ABL positive chronic myeloid leukemia with concurrent JAK2V617F positive myelodysplastic syndrome/myeloproliferative neoplasm (RARS-T). Am J Hematol 84: 306-307.

10. Bornhäuser M, Mohr B, Oelschlaegel U, Bornhäuser P, Jacki S, et al. (2007) Concurrent JAK2(V617F) mutation and BCR-ABL translocation within committed myeloid progenitors in myelofibrosis. Leukemia 21: 1824-1826.

11. Go RS (2007) Myeloproliferative disorders with coexisting BCR-ABL translocation and JAK2 V617F mutation. Leukemia 21: 2051.

12. Pastore F, Schneider S, Christ O, Hiddemann W, Spiekermann K (2013) Impressive thrombocytosis evolving in a patient with a BCR-ABL positive CML in major molecular response during dasatinib treatment unmasks an additional JAK2V617F. Experimental Hematology \& Oncology 2: 1-5.

13. Wang X, Tripodi J, Kremyanskaya M, Blouin A, Roda P, et al. (2013) BCR-ABL1 is a secondary event after JAK2V617F in patients with polycythemia vera who develop chronic myeloid leukemia. Blood 121: 1238-1239.

14. Hussein K, Bock O, Seegers A, Flasshove M, Henneke F, et al. (2007) Myelofibrosis evolving during imatinib treatment of a chronic myeloproliferative disease with coexisting BCR-ABL translocation and JAK2V617F mutation. Blood 109: 4106-4107.
15. Xu W, Chen B, Tong X (2014) Chronic myeloid leukemia patient with cooccurrence of BCR-ABL junction and JAK2 V617F mutation. Int J Hematol 99 87-90.

16. Ursuleac I, Colita A, Adam T, Jardan C, llea A, et al. (2013) The concomitant occurrence of JAK2V617F mutation and BCR/ABL transcript with phenotypic expression - an overlapping myeloproliferative disorder or two distinct diseases? - case report. J Med Life 6: 34-37.

17. Lee Y, Moon J, Shin J, Won J, Han S, et al. (2013) Two CML patients who subsequently developed features of essential thrombocythemia with JAK2V617F mutation while in complete cytogenetic remission after treatment with imatinib mesylate. Int J Hematol 97: 804-807.

18. Jones AV, Kreil S, Zoi K, Waghorn K, Curtis C, et al. (2005) Widespread occurrence of the JAK2 V617F mutation in chronic myeloproliferative disorders. Blood 106: 2162-2168

19. Chen Q, Lu P, Jones A, Cross N, Silver R, et al. (2007) Consultation in Molecular Diagnostics: Amplification Refractory mutation system, a highly sensitive and simple polymerase chain reaction assay, for the detection of JAK2 V617F mutation in chronic myeloproliferative disorders. JMD 9: 272-276. 